\title{
Removal of Cibacet Blue (CB) BY AdSORPTION ONTO AN Algerian RED SLAG
}

\author{
Fatima Teboul ${ }^{1}$, Mohamed Wahib Naceur ${ }^{1}$, Benamar Cheknane ${ }^{1}$ and Abdelhak \\ Maazouzi ${ }^{2}$ \\ ${ }^{1}$ Hydrogen Energetical Application Laboratory (HEAL), Department of Chemical \\ Engineering .University of Blida, Soumaa, 9000 Blida, Algeria \\ ${ }^{2}$ laboratoire ENERGARD University of Béchar, Algeria \\ wnaceur@mail.univ-blida.dz
}

(Received January 2019 - Accepted January 2020)

\begin{abstract}
Teboul, F., Naceur, M. W., Cheknane, B., \& Maazouzi, A. (2020). Removal of Cibacet Blue (CB) by Adsorption onto an Algerian Red Slag. Lebanese Science Journal, 21(1), 24-36.

This study is based on the implementation of a composite material with absorbent properties for the elimination of organic pollutants. In our case we used the slag (red slag) from the region of Bechar, (South-East of Algeria). Characterization using DRX and Fourier transforms infrared spectrometer (FT-IR), shows that, we were able to prepare adsorbents with very interesting structural and mechanical properties. The effectiveness of obtained adsorbents was evaluated in the removal of Cibacet Blue (CB) dye using the adsorption process. Kinetic results with an elimination rate of $83 \%$ show that, the time to equilibrium is influenced by experimental conditions such us, contact time, $p H$, initial concentration, temperature and adsorbent mass. Pseudo-first order model represent very well our experimental results with adjustment coefficients $\left(R^{2}\right)$ close to 1. Modeling of adsorption isotherms of the $C B$ dye on the red slag shows that both models of Langmuir and Freundlich can present our results with acceptable adjustment coefficients $\left(R^{2}>0.995\right)$.
\end{abstract}

Keywords: red slag, adsorption, Cibacet, adsorption isotherms, thermodynamics.

\section{INTRODUCTION}

Water which is a common heritage for all humanity, can significantly affect individual and collective health, agriculture, industry and domestic life...etc. There is no access to the production of wealth without access to water. In some countries such as Algeria, water pollution remains one of the major concerns because of limited, conventional processes to ensure a satisfactory treatment of polluted water. For that, it is necessary to design global and sustainable solutions through an original process for the treatment of any polluted water (Abel, 2012).

Algerian industrial effluents are part of the most poorly treated wastewater and are characterized by strong colorations, strong variations of $\mathrm{pH}$ and high chemical oxygen demands (COD) (Rana et al., 2004). In order to treat these effluents, several processes are 
used based on the type of water to be treated. Adsorption is one of the most used processes because of its ease of use and the efficiency for the elimination of organic and/or inorganic pollutants from water. Elimination efficiency of such process is directly related to the nature of used adsorbent that can be of biological, mineral or organic origin. Several adsorbents showed better efficiency for the elimination of pollutants such us, activated carbon, pillared clay...etc. But the very high costs of these adsorbents push the researchers from around the world to find other natural adsorbents (Chavan, 2011). In this perspective, we are interested developing an original and innovative process for the adsorption of industrial effluents (dyes) using locally available red slag (from Algeria) which can be considered as a new adsorbent for the treatment of water contaminated by textile dye. The dye used is "Cibacet Blue (CB)"; it is an anthraquinone dye. Its chemical name is 1-methylamino-4-(beta-hydroxyethylamino) anthraquinone. It has been used as a dye for nylon, cellulose, polyester, and acrylate fibers. It has also been used to dye the exterior of the thermoplastics and in semi-permanent formulations for hair dye at concentrations less than $1 \%$.

\section{MATERIALS AND METHODS}

\section{Characteristics of adsorbate}

Table 1 summarizes the properties of Cibacet Blue (CB) dye.

Table 1. Main characteristics of blue cibacet $(\mathrm{CB})$ dye.

\begin{tabular}{|l|l|}
\hline Dye & Cibacet Blue (CB) \\
\hline Structure & \\
& \\
\hline Chemical formula & C $17 \mathrm{H}_{16} \mathrm{~N}_{2} \mathrm{O}_{3}$ \\
\hline Molar mass $(\mathrm{g} / \mathrm{mol})$ & 636.325 \\
\hline Maximum wave length $\lambda \max (\mathrm{nm})$ & $332^{\circ} \mathrm{C}$ \\
\hline melting point & Acetone, ethanol, benzene, linseed oil \\
\hline Soluble in & \\
\hline
\end{tabular}

\section{Characterization of adsorbent (red slag)}

The following methods are used to characterize adsorbent: The FTIR spectroscopy is used to confirm the slag components based on the chemical functional groups. The crystalline structure of Red slag was obtained by X-ray diffraction (XRD) recorded on (BRUKER D2 PHASER) powder diffractometer $(\mathrm{Cu}$ Ka radiation, $\mathrm{k}=$ $1.5418 \AA$ ). 
The isoelectric point was determined by preparing series of $\mathrm{NaCl}$ solutions $(0.1 \mathrm{~N})$ at different initial $\mathrm{pH}$ ranging from 3 to $12 \mathrm{pH}$ was adjusted by addition of $\mathrm{HCl}(0.1 \mathrm{~N})$ and $\mathrm{NaOH}(0.1 \mathrm{~N})$ (Zermane et al., 2005). To each solution, $0.1 \mathrm{~g}$ of adsorbent (red slag) was added, and the solutions were stirred for 48 hours. The samples were filtered and $\mathrm{pH}$ was measured. PZC was determined by drawing the curve presenting the difference between the initial and final $\mathrm{pH}$ in function of the initial $\mathrm{pH}$. (Elqada et al., 2006) (Ghazi Mokri et al., 2015).

\section{Application of Cibacet Blue in adsorption}

The Cibacet Blue (CB) dye was chosen as an organic pollutant. To carry out the adsorption kinetics using red slag, the protocol given by (Chennouf et al., 2015) was followed. Adsorption tests were performed in series of reagent bottles at constant temperature of $25^{\circ} \mathrm{C}$, by mixing $0.05 \mathrm{~g}$ of red slag with $50 \mathrm{~mL}$ of $\mathrm{CB}$ aqueous solution $(0.04 \mathrm{~g} / \mathrm{l}) . \mathrm{pH}$ of the obtained solution is 6.5 which is the nature $\mathrm{pH}$. All kinetic adsorption experiments were conducted at this $\mathrm{pH}$. In order to determine the maximum adsorption, adsorption isotherms were carried out by adding different quantities of sorbent (from 0.01 to $0.1 \mathrm{~g}$ ) to $50 \mathrm{~mL}$ of the $\mathrm{CB}$ solutions. The experimental results are expressed as percentage adsorption capacity which is defined as follows:

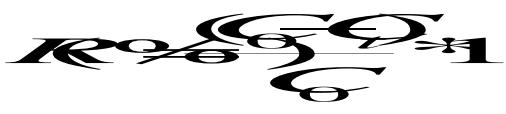

Where $C_{O}$ is the initial concentration of adsorbent in $(\mathrm{mg} / \mathrm{l}), C_{t}$ is the adsorbent concentration at time $\mathrm{t}$ in ( $\mathrm{mg} / \mathrm{l})$. (Santhi et al., 2009) and Qt is the adsorption capacity:

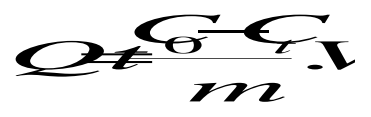

Where $\mathrm{V}$ is the volume of the adsorbed solution $(\mathrm{ml}), m$ is the mass of the adsorbent $(\mathrm{mg}$ ) (Faling et al., 2016).

\section{RESULTS AND DISCUSSION}

\section{Characterization results}

The natural slag of Bechar, (south-East of Algeria) has very interesting properties in water treatment by adsorption even in its raw state (See figure 1). 


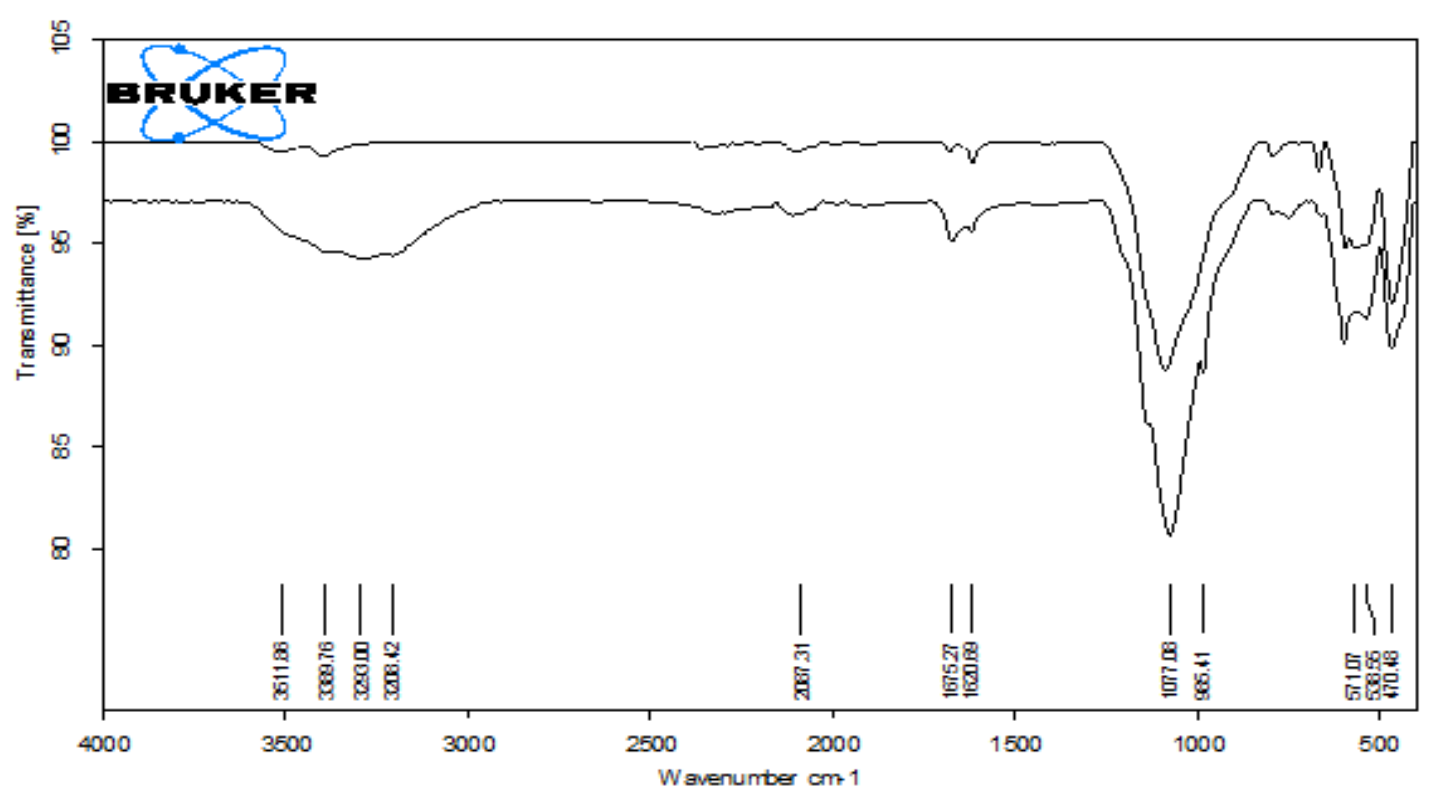

Figure 1. Infrared Spectrum of the slag: (a) before adsorption, (b) after adsorption.

Figure 2 shows the red slag Infrared spectrum. According to maximums peaks, the components of the slag were confirmed. Compared to the literature, the adsorbent has a montmarillonitic character (Kacha et al., 1997), with a report of $\mathrm{SiO}_{2} / \mathrm{Al}_{2} \mathrm{O}_{3}=2.23$ (See Table 2).

Table 2. The chemical composition of slag.

\begin{tabular}{|l|c|c|c|c|c|c|}
\hline Component \% & $\mathrm{SiO}_{2}$ & $\mathrm{Al}_{2} \mathrm{O}_{3}$ & $\mathrm{SO}_{3}$ & $\mathrm{MgO}$ & $\mathrm{CaO}$ & $\mathrm{Fe}_{2} \mathrm{O}_{3}$ \\
\hline Red slag & 62.7 & 28 & 0.8 & 1 & 1.5 & 6 \\
\hline
\end{tabular}

Slag consists of different rock fragments, including small pieces of coal, but in small quantities and also different heavy minerals. In addition, the investigated slag includes fragments of rock or minerals very identical at slightly different proportions (Table 3).

Table 3. Result of mineralogical and petrographic analysis of the slag.

\begin{tabular}{|l|l|}
\hline Minerals and fragments & $(\%)$ \\
\hline Calcite & $1 \%$ \\
\hline Coal Fragments & $3 \%$ \\
\hline Fragments of black schist & $10 \%$ \\
\hline Fragments of red schist & $35 \%$ \\
\hline White sandstone & $15 \%$ \\
\hline psammite I & $33 \%$ \\
\hline Wind sand & $3 \%$ \\
\hline Total & $100 \%$ \\
\hline
\end{tabular}


Figure 2 presents the X-ray diffraction of used Red slag.it can be seen from the diagram that the adsorbent is composed of number of peaks which indicate the complex nature of the material.

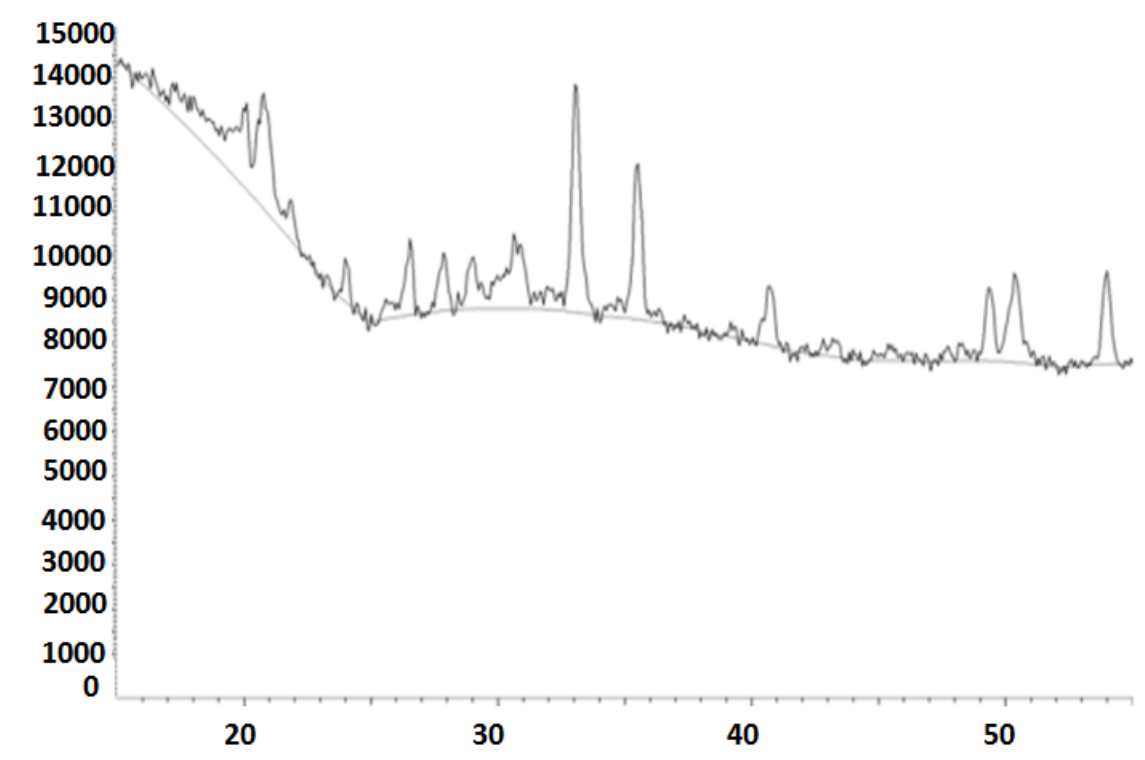

Figure 2. DRX diagram of the slag.

The physical characteristics of used adsorbent are summarized in Table 4. These characteristics show that the used adsorbent has significant physical properties with extragranular porosity exceeding $30 \%$.

Table 4. The physical characteristics of slag.

\begin{tabular}{|l|l|}
\hline Parameter & Slag \\
\hline Fineness module & 4.52 \\
\hline Effective diameter $\mathrm{d}_{10}(\mathrm{~mm})$ & 0.16 \\
\hline Coefficient of uniformity $(\mathrm{CU})$ & 2.95 \\
\hline Specific air of the material cm ${ }^{-1}(\mathrm{As})$ & 19.4 \\
\hline Density abs $\rho(\mathrm{kg} / \mathrm{m} 3)$ & 1.90 \\
\hline Porosity $(\varepsilon)(\%)$ & 38.81 \\
\hline
\end{tabular}

The PZC values allow to determine the acidic or basic nature of the Red slag and to know, according to the $\mathrm{pH}$ of the solution, its net surface charge. Results given by the figure 3 , show that the red slag has a surface of acid functional groups with a PZC $=6.8$. 


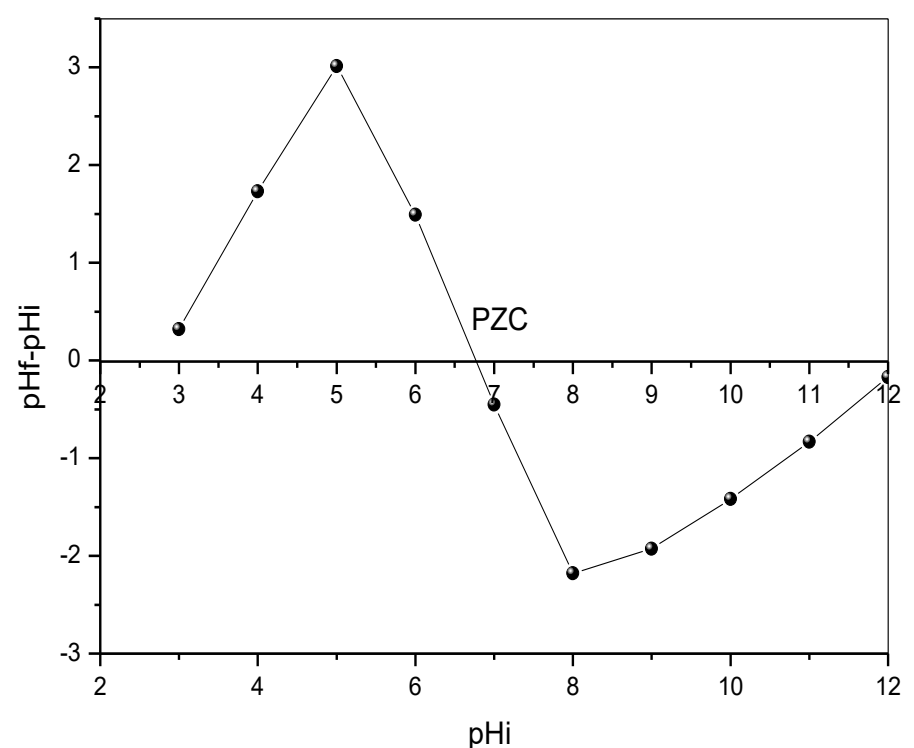

Figure 3. Zero point of charge of red slag curve (PZC).

\section{Kinetic adsorption}

A kinetic adsorption curve of the CB by the red slag is presented as the adsorbed amount and the percentage of adsorption capacity (Santhi et al., 2009) relative to time (see figure 4). It is noted that the kinetic adsorption of CB is composed of two phases: a very fast phase in the time ranging from 1 to $35 \mathrm{~min}$, followed by a very slow phase which represents the state of equilibrium (percentage of elimination $\mathrm{R}=77 \%$ ) for an interval from 35 to $60 \mathrm{~min}$. This can be explained by the fact that the adsorption sites are open and easily accessible at the beginning, so the $\mathrm{CB}$ molecules interact easily with these sites.

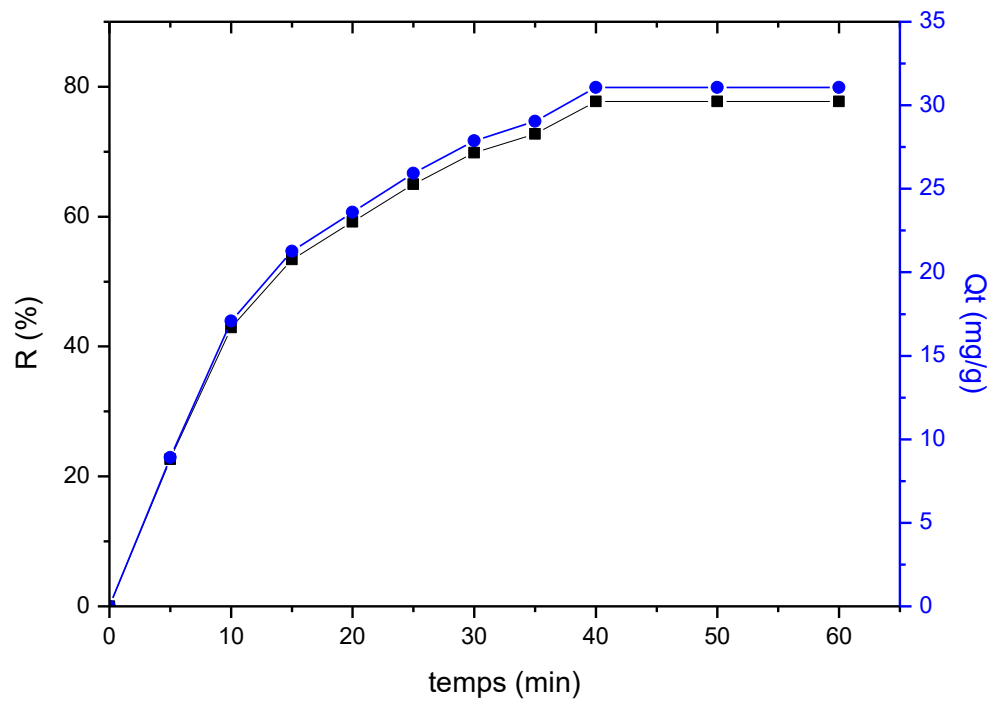

Figure 4. CB dye adsorption kinetics $\left(\mathrm{m}=1 \mathrm{~g} / \mathrm{l},[\mathrm{CB}]=40 \mathrm{mg} / \mathrm{l}, \mathrm{T}=25^{\circ} \mathrm{C}\right.$., $\mathrm{V}=$

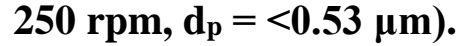

In this section, the parameters influencing the kinetic adsorption of CB by red slag are studied. These parameters are given as follows: 


\section{- $\quad$ Effect of initial dye concentration}

The evolution of the adsorbed amount of CB by the red slag as a function of the contact time at different initial concentrations of CB (5 to $100 \mathrm{mg} / 1)$ is represented by figure 5 .

The figure shows that the equilibrium time and the adsorption capacity are strongly dependent of the initial concentration.

When the initial dye concentration increases the available adsorption sites are increasingly occupied till saturation. At this time, the adsorption becomes difficult leading to the decrease of adsorption efficiency. In other word, at low dye concentrations, the available adsorption sites are easily occupied, which implies very high adsorption efficiency (Miyah et al., 2015) (Abdallah et al., 2016).

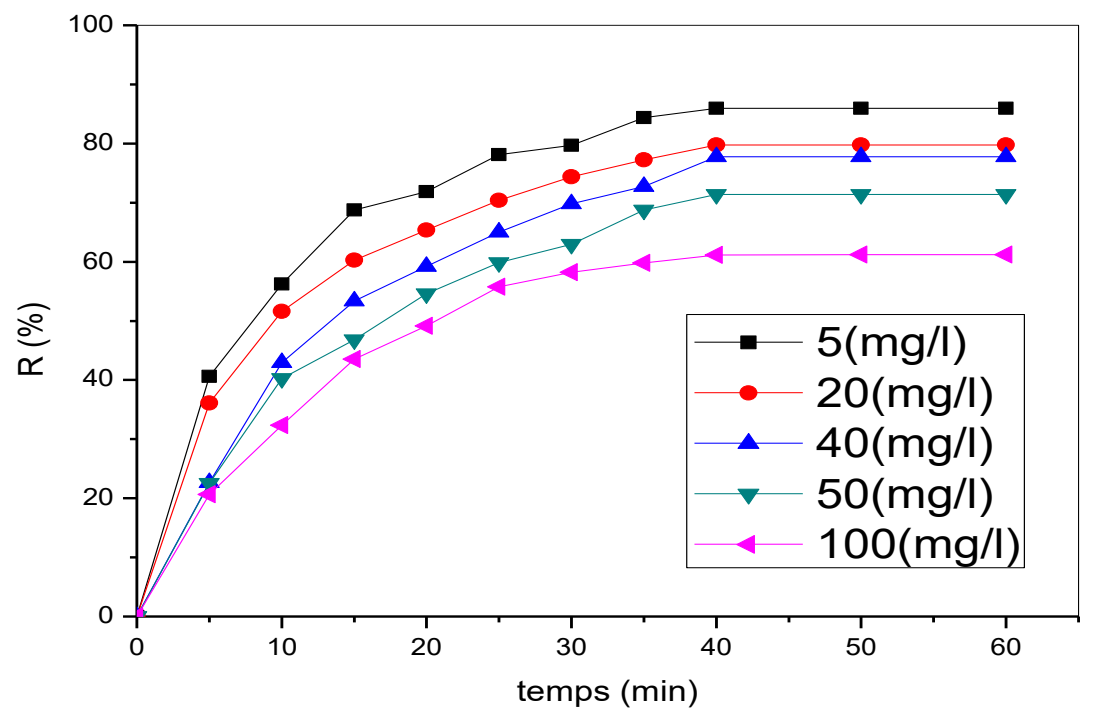

Figure 5. Effect of contact time on $\mathrm{CB}$ dye removal $\left(\mathrm{m}=1 \mathrm{~g} / \mathrm{l}, \mathrm{T}=25^{\circ} \mathrm{C}, \mathrm{V}=\mathbf{2 5 0}\right.$ rpm, $\left.d_{p}=<0.53 \mu \mathrm{m}\right)$.

\section{- $\quad$ Effect of $\mathbf{p H}$}

The elimination of pollutant from simulated aqueous solution by adsorption is extremely influenced by the $\mathrm{pH}$ medium of the solution which can strongly affects the nature of the adsorbent surface charge, the ionization of the adsorbate extent and the adsorption rate. The adsorption process is affected by $\mathrm{pH}$ change (Khattria \& Singh, 2009).

The adsorption of $\mathrm{CB}$ increases with the increasing $\mathrm{pH}$ of the solution. According to data presented in figure 6 , the best value of adsorption capacity, $Q_{e}=29.2 \mathrm{mg} / \mathrm{g}$, was recorded at $\mathrm{pH} 3$. And this can be explained by the very high interaction between the sites of red slag and CB molecules. The slag is positively-charged and the $\mathrm{CB}$ in its molecular state is negatively-charged. Consequently, the interaction between them is highly polarized due to charge difference. 


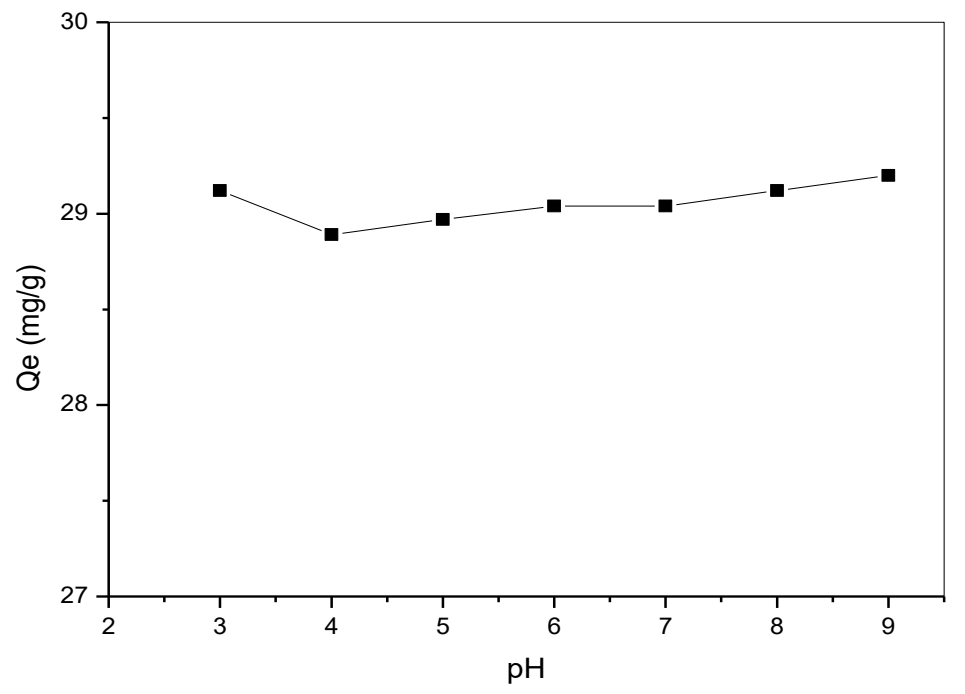

Figure 6. Effect of pH on the adsorption capacity of CB dye.

\section{- Effect of stirring rate on adsorption of CB dye}

The evolution of the adsorption amount of $\mathrm{CB}$ by red slag as function of the stirring speed is presented in Figure 7. The figure illustrates that the optimal stirring speed for the adsorption dye is reached starting to $250 \mathrm{rpm}$. This is due to the good dispersion of the used adsorbent in the solutions, leading to better contact rate adsorabent-adsorbate (Annouar \& Soufiane, 2005).

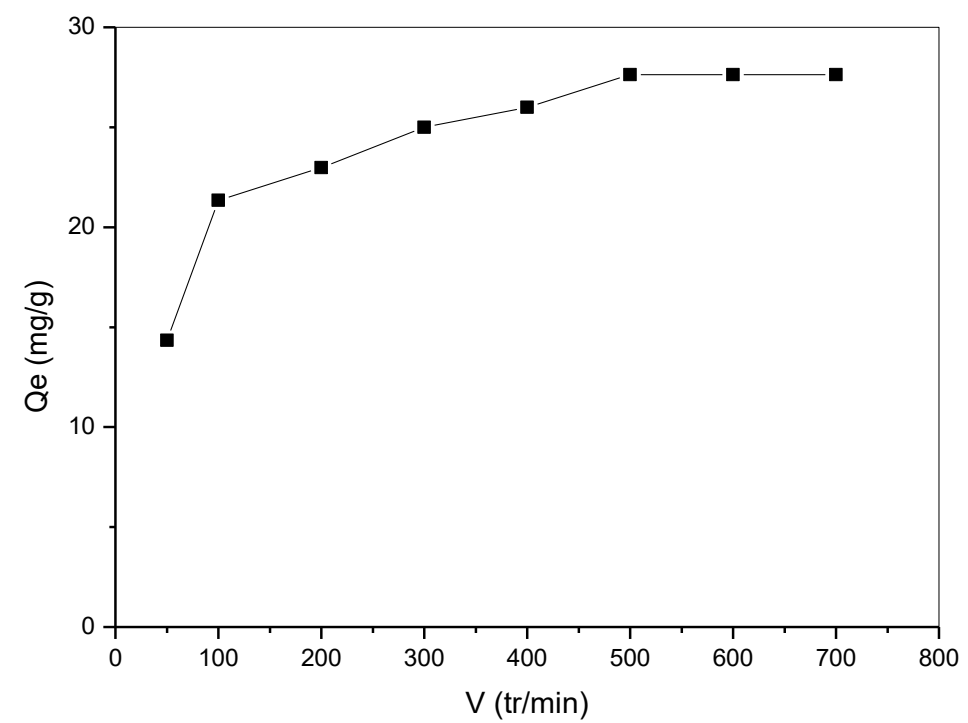

Figure 7. Effect of stirring on the adsorption capacity ([CB]= $40 \mathrm{mg} / \mathrm{l}, \mathrm{m}=\mathbf{\mathrm { g }} / \mathrm{l}$, $\mathrm{d}_{\mathrm{p}}=<53 \mu \mathrm{m}, \mathrm{T}=20^{\circ} \mathrm{C}$ and $\mathrm{pH}=6.50$, time $\left.=20 \mathrm{~min}\right)$.

\section{- $\quad$ Effect of size of the adsorbent particles}

The effect of size of the red slag on the kinetic adsorption of CB was studied by varying this parameter from 50 to $2500 \mu \mathrm{m}$. the obtained results are given in figure 8 . It shows that the rate of adsorption is directly related to the size of adsorbent. The increase of $\mathrm{dp}$ (pore diameter) leads to decrease the adsorption amount of CB by red slag. This can 
be explained by the fact that the more the slag is small, the larger is the contact surface. (Cheknane et al., 2012).

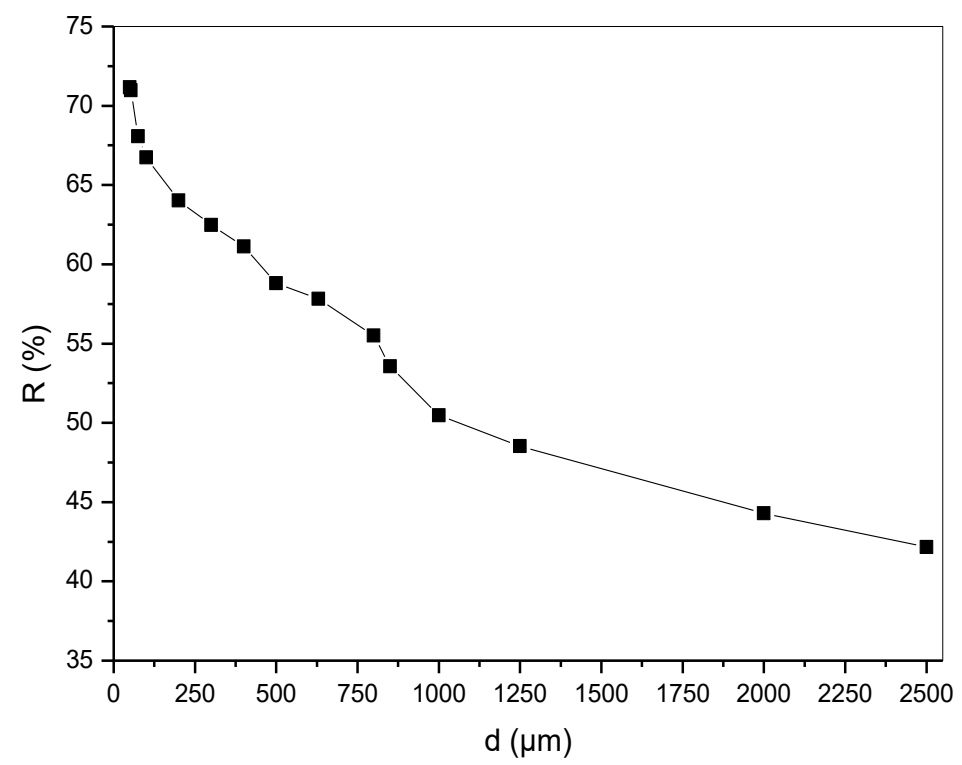

Figure 8. Effect of pore diameter on adsorption capacity. ([CB] $=40 \mathrm{mg} / \mathrm{l}, \mathrm{m}=1$ $\mathrm{g} / \mathrm{l}, \mathrm{T}=20^{\circ} \mathrm{C}$ and $\left.\mathrm{pH}=6.50, \mathrm{v}=250 \mathrm{rpm}\right)$.

\section{Order of kinetic adsorption}

In order to investigate the mechanism of $\mathrm{CB}$, the two models of the chemical reaction were applied to the experimental data. The pseudo-first- and pseudo-secondorder models were used to specify the adsorption mechanism (Baliti et al., 2014) (Li et al., 2009).

$$
\begin{array}{r}
q=q_{e}\left(1-e^{-k 1 t}\right) \\
q=\frac{q_{e}^{2} k_{2} t}{1+q_{e} k_{2} t}
\end{array}
$$

Where $\mathrm{q}_{\mathrm{e}}$ and $\mathrm{q}\left(\mathrm{mg} \mathrm{g}^{-1}\right)$ are the amount of dye adsorbed at equilibrium and time $\mathrm{t}(\mathrm{min})$, $\mathrm{k}_{1}\left(\mathrm{~min}^{-1}\right)$ is the pseudo-first rate constant and $\mathrm{k}_{2}\left(\mathrm{~g} \mathrm{mg}^{-1} \mathrm{~min}^{-1}\right)$ is the pseudo-second-order model (Talal, 2014) (Zermane et al., 2013).

The corresponding constant rates $\mathrm{k}_{1}$ and the correlation coefficients $\left(\mathrm{R}^{2}\right)$ values are summarized in Table 5. The obtained results showed that the pseudo-first order model $\left(R^{2}=0.996\right)$ gave the best correlation than the second one $\left(R^{2}=0.991\right)$. 
Table 5. Kinetic parameters evaluated for CB adsorption onto slag.

\begin{tabular}{|l|l|l|}
\hline Model & Parameters & values \\
\hline \multirow{4}{*}{ Pseudo first order } & $\mathrm{K}_{1}\left(\mathrm{~min}^{-1}\right)$ & 0.070 \\
\cline { 2 - 3 } & $\mathrm{Q}_{\text {e.cal }}(\mathrm{mg} / \mathrm{g})$ & 31.873 \\
\cline { 2 - 3 } & $\mathrm{Q}_{\text {e.exp }}(\mathrm{mg} / \mathrm{g})$ & 31.060 \\
\cline { 2 - 3 } & $\mathrm{R}^{2}$ & 0.996 \\
\hline \multirow{5}{*}{ Pseudo second order } & $\mathrm{K}_{2}(\mathrm{~g} / \mathrm{mg} \cdot \mathrm{min})$ & 0.001 \\
\cline { 2 - 3 } & $\mathrm{Q}_{\text {e.cal }}(\mathrm{mg} / \mathrm{g})$ & 40.116 \\
\cline { 2 - 3 } & $\mathrm{Q}_{\text {e.exp }}(\mathrm{mg} / \mathrm{g})$ & 31.060 \\
\cline { 2 - 3 } & $\mathrm{R}^{2}$ & 0.991 \\
\hline
\end{tabular}

\section{Adsorption isotherms}

Adsorption isotherms of CB by red slag are presented in figure 9. It is showed that the evolution of the adsorption capacities relative to residual concentrations of dye (Senturk et al., 2010) and show also a high affinity of red slag towards CB molecules with an adsorption capacity close to $60 \mathrm{mg} / \mathrm{g}$. Modeling results show clearly that the obtained equilibrium isotherm is in close agreement with Langmuir equation (Langmuir, 1918), as the correlation coefficient $\left(\mathrm{R}^{2}\right)$ values reach 0.988 . In our case, isotherm constants were calculated using non-linear regression (Hamad et al., 2018).

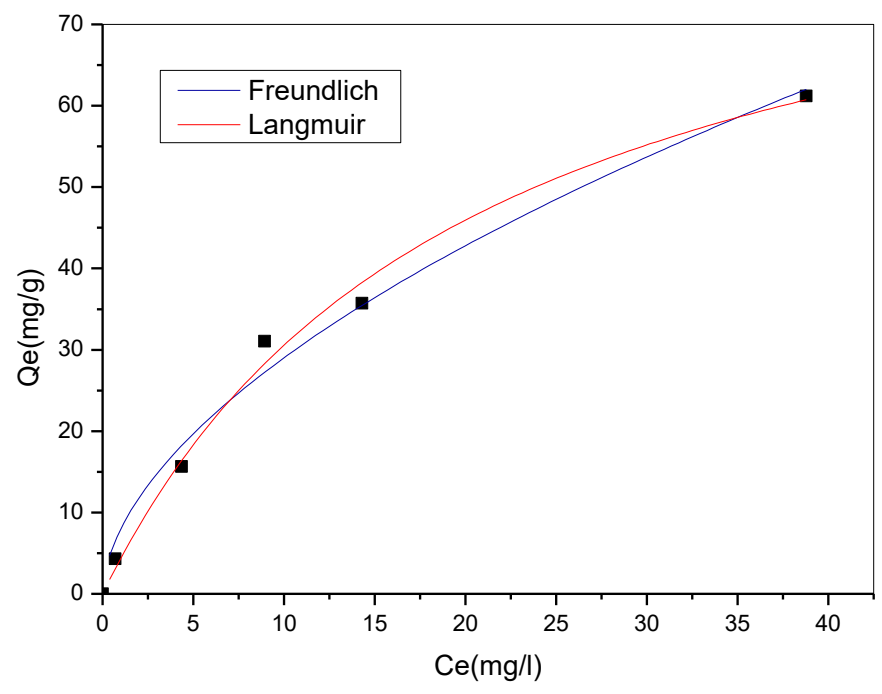

Figure 9. Langmuir and Freundlich isotherms for the adsorption of CB by the slag.

\section{Thermodynamic parameters of adsorption}

Thermodynamic parameters of the adsorption of CB by red slag such as, enthalpy $\left(\Delta \mathrm{H}^{\circ}\right)$, entropy $\left(\Delta \mathrm{S}^{\circ}\right)$ and free energy $\left(\Delta \mathrm{G}^{\circ}\right)$ of activation (Table 6), were determined at different temperature (from 10 to $40^{\circ} \mathrm{C}$ ) (Saman et al., 2007) using the following equations (Dawood \& Sen, 2012.), (Yu \& Luo, 2014): 


$$
\begin{aligned}
\ln K_{d} & =\frac{\Delta S^{\circ}}{R}-\frac{\Delta H^{\circ}}{R T} \\
\Delta G^{\circ} & =\Delta H^{\circ}-T \Delta S^{\circ}
\end{aligned}
$$

Where $\mathrm{Kd}=\mathrm{Qe} / \mathrm{Ce}$ is the distribution coefficient, $\mathrm{T}$ is solution temperature in Kelvin (K). $\mathrm{R}$ is the constant of the perfect gases $(\mathrm{R}=8.314 \mathrm{~J} / \mathrm{mol} . \mathrm{K})$.

Table 6. Isotherms parameters of the adsorption process of the CB by slag.

\begin{tabular}{|l|l|l|}
\hline Models & Parameters & values \\
\hline \multirow{4}{*}{ Langmuir isotherm } & $\mathrm{K}_{\mathrm{L}}\left(\mathrm{min}^{-1}\right)$ & 0.049 \\
\cline { 2 - 3 } & $\mathrm{Q}_{\mathrm{e} . \mathrm{cal}}(\mathrm{mg} / \mathrm{g})$ & 92.417 \\
\cline { 2 - 3 } & $\mathrm{R}^{2}$ & 0.988 \\
\hline \multirow{3}{*}{ Freundlich isotherm } & $\mathrm{K}_{\mathrm{F}}(\mathrm{g} / \mathrm{mg} . \mathrm{min})$ & 7.954 \\
\cline { 2 - 3 } & $n_{\mathrm{F}}$ & 0.560 \\
\cline { 2 - 3 } & $\mathrm{R}^{2}$ & 0.980 \\
\hline
\end{tabular}

The obtained results relative to the thermodynamic study (See table 7) show that Gibbs free energy change is negative and decreases when temperature increases, which indicates the spontaneous process in our case (Ahmad \& Kumar, 2010).

\begin{tabular}{|c|c|c|c|}
\hline $\mathbf{T}\left({ }^{\circ} \mathbf{C}\right)$ & $\Delta G^{\circ}(\mathrm{KJ} / \mathrm{mol})$ & $\Delta H^{\circ}(\mathrm{KJ} / \mathrm{mol})$ & $\Delta \mathrm{S}^{\circ}(\mathrm{J} / \mathrm{mol} . \mathrm{K})$ \\
\hline 10 & -2.072 & \multirow{4}{*}{93.032} & \multirow{4}{*}{336.059} \\
\hline 20 & -5.433 & & \\
\hline 30 & -7.113 & & \\
\hline 40 & -12.154 & & \\
\hline
\end{tabular}

Table 7. Thermodynamic parameters of the adsorption process of the CB by slag.

The positive values of $\Delta \mathrm{H}^{\circ}$, implies that the process of the adsorption is endothermic and a higher temperatures facilitate the uptake of $\mathrm{CB}$ molecules by adsorption by red slag.

The positive value of $\Delta \mathrm{S}^{\circ}$ indicates that the molecules of the $\mathrm{CB}$ remain less ordered on the interface solids / solution during the process of adsorption (Colak et al., 2009).

\section{CONCLUSION}

In This study, the adsorption process of Cibacet blue (CB) by red slag was investigated. The results show that the percentage of elimination (which can reached $80 \%$ ) is strongly influenced by the operational conditions such as, contact time, $\mathrm{pH}$, initial dye concentration and size of adsorbent. In addition, the temperature has a favorable effect on the percentage of dye removal, suggesting that the adsorption of CB on slag was a spontaneous endothermic process. The Modeling of adsorption kinetics reveals that the pseudo-second-order model offers a better correlation of the kinetic data with an 
adjustment coefficient higher than 0.995. Isotherms were best described using the Langmuir model with $\mathrm{R}^{2}$ of 0.99 , which indicates that the $\mathrm{CB}$ dye molecules are adsorbed in monolayers and without any interactions among them. The obtained results reveal that the red slag is a potential low cost adsorbent that can be used effectively for the treatment of effluents from the textile industry.

\section{REFERENCES}

Abel, A. (2012). Colour Design Theories and Applications. A volume in Woodhead Publishing Series in Textiles, 433-470 pp.

Abdallah, M., Hijazi, A., Hamieh, M., Alameh, M., Toufaily, J., \& Rammal, H. (2016). Treatment of industrial wastewater using a natural and biodegradable adsorbent based on Eucalyptus Mira. J. Mater. Environ. Sci, 7(11), 4036-4048.

Annouar, S., \& Soufiane, A. (2005). Mountadar, M. Université d'El jedida-Maroc Revue Francophone d'ecologie industrielle, (37), $1^{\mathrm{er}}$ trimester.

Ahmad, R., \& Kumar, R. (2010). Adsorptive of Congo red dye from aqueous solution using bael shell carbon. Appl. Surf. Sci, 257, 1628-1633.

Baliti, J., Asnaoui, A., \& Abouarnadasse, S. (2014). L'élimination du bleu de méthylène par une argile naturelle de Taza en milieu aqueux. International Journal of Innovative Research in Advanced Engineering (IJIRAE), 1(6).

Chavan, R. B. (2011). Environmentally friendly dyes, In Woodhead Publishing Series in Textiles, edited by Clark M, Woodhead Publishing, Handbook of Textile and Industrial Dyeing, 16(1), 515-561.

Cheknane, B., Baudu, M., Basly, J. P., Bouras, O., \& Zermane, F. (2012). Modeling of basic green 4 dynamic sorption onto granular organo-inorgano pillared clays (GOiCs) in column reactor. Chemical Engineering Journal, 209, 7-12.

Chennouf, Z., Cheknane, B., Zermane, F., Gaigneaux, E. M., Hadj Sadok, A. B., Mohammedi, O., \& Bouchenafa, N. (2015). Preparation of activated carbon based of synthetic and agricultural wastes: application to the adsorption of methyl orange. Energies Renouvelables Journal, 18(4), 575-586.

Colak, F., Atar, N., \& Olgun, A. (2009). Biosorption of acidic dyes from aqueous solution by Paenibacillusmacerans: kineti, thermodynamic and equilibrium studies. Chem. Eng. J., 150, 122-130.

Dawood, S., \& Sen, T. K. (2012). Author's responses to the comment by Canzano et al. and also corrigendum to Removal of anionic dye Congo red from aqueous solution by raw pine and acid-treated pine cone powder as adsorbent: Equilibrium, thermodynamic, kinetics, mechanism and process design published in Water Research. Separation Science and Technology, 46, 4316-4317.

Elqada, E. N., Allen, S. J., \& Walker, G. M. (2006). Adsorption of Methylene Blue onto activated carbon produced from steam activated bituminous coal: a study of equilibrium adsorption isotherm. Chem. Eng. J., 124, 103-110.

Faling, L., Liang, F., \& Yi, Lu. (2016). A novel CoFe layered double hydroxides adsorbent: High adsorption amount for methyl orange dye and fast removal of $\mathrm{Cr}$ (VI). Journal of Microporous and Mesoporous Materials, 234, 230-238.

Ghazi Mokri, H. S., Modirshahl, N., Behnajady, M. A., \& Vahid, B. (2015). Adsorption of C.I. Acid Red 97 dye from aqueous solution onto walnut shell: kinetics, thermodynamics parameters, isotherms. Int. J. Environ. Sci. Technol., 12, 14011408. 
Hamad, T., Benmaamar, Z., Nedjioui, M., \& Boucherit, A. (2018). Use of activated carbon from sapindus for the adsorption of methylene blue. Lebanese Science Journal, 19(1), 112-122.

Kacha, S., Ouali, M. S., \& Elmaleh, S. (1997). Dye abatement of textile industry wastewater with bentonite and aluminium salts. Revue des sciences de l'eau. 2 , 233-248.

Khattria, S. D., \& Singh, M. K. (2009). Removal of malachite green from dye wastewater using neem sawdust by adsorption. Journal of Hazardous Materials, 167, 10891094.

Langmuir, I. (1918). The Adsorption of Gases on Plane Surfaces of Glass, Mica and Platinium'. Journal of the American Chemical Society, 40(9), 1361-1403.

Li, Y., Gao, T., Sun, D., Li, X., Wang, B., \& Lu, F. (2009). Hexavalent chromium removal from aqueous solution by adsorption on aluminum magnesium mixed hydroxide. Water Research, 43, 3067-307.

Miyah, Y., Idrissi, M., \& Zerrouq, F. (2015). Study and Modeling of the Kinetics Methylene blue Adsorption on the Clay Adsorbents (Pyrophillite, Calcite). J. Mater. Environ. Sci., 6(3), 699-712.

Rana, T., Gupta, S., Kumar, D., Sharma, S., Rana, M., Rathore, V. S., \& Pereira, M. J. (2004). Environ. J. Toxicol. Pharmacol., 18(1), 1-7.

Saman, M., El-Eswed, B., \& Khalili, F. (2007). Adsorption of humic Acid on bentonite. Applied Clay Science, 38, 51-56.

Senturk, H. B., ozdes, D., \& Duran, C. (2010). Desalination. 252, 81-87.

Santhi, T., Manonmani, S., Smitha, T., \& Mahalakshmi, K. (2009). Adsorption kinetics of cationic dyes from aqueous solution by bioadsorption onto activated carbon prepared from Cucumis Sativa. Journal of Applied Sciences in Environmental Sanitation, 4(3), 263-271.

Talal, S. (2014). Sorption kinetics: Obtaining a pseudo-second order rate equation based on a mass balance approach. Journal of Environmental Chemical Engineering, (2), 1001-1006.

Yu, L., \& Luo, Y-M. (2014). The adsorption mechanism of anionic and cationic dyes by Jerusalem artichoke stalk-based mesoporous activated carbon. J. Environ. Chem. Eng, 2, 220-229.

Zermane, F., Cheknane, B., Basly, J. P., Bouras, O., \& Baudu, M. (2013). Influence of humic acids on the adsorption of Basic Yellow 28 dye onto an iron organoinorgano pillared clay and two Hydrous Ferric Oxides. Journal of Colloid and Interface Science, 395, 212-216.

Zermane, F., Naceur, M. W., Cheknane, B., \& Ait Messaoudane, N. (2005). Adsorption of humic acids by a modified Algerian montmorillonite in synthesized seawater. Desalination, 179, 375-380. 